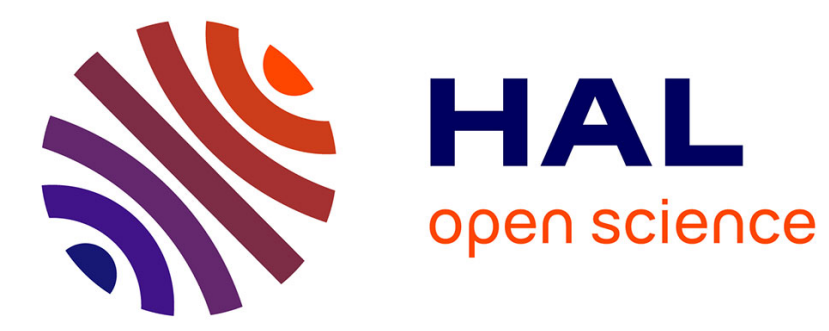

\title{
Desmoplastic stroma reaction in papillary thyroid microcarcinoma
}

\author{
Oskar Koperek, Reza Asari, Bruno Niederle, Klaus Kaserer
}

\section{To cite this version:}

Oskar Koperek, Reza Asari, Bruno Niederle, Klaus Kaserer. Desmoplastic stroma reaction in papillary thyroid microcarcinoma. Histopathology, 2011, 58 (6), pp.919. 10.1111/j.1365-2559.2011.03791.x . hal-00630794

\section{HAL Id: hal-00630794 https://hal.science/hal-00630794}

Submitted on 11 Oct 2011

HAL is a multi-disciplinary open access archive for the deposit and dissemination of scientific research documents, whether they are published or not. The documents may come from teaching and research institutions in France or abroad, or from public or private research centers.
L'archive ouverte pluridisciplinaire HAL, est destinée au dépôt et à la diffusion de documents scientifiques de niveau recherche, publiés ou non, émanant des établissements d'enseignement et de recherche français ou étrangers, des laboratoires publics ou privés. 


\section{Histopathology}

\section{Desmoplastic stroma reaction in papillary thyroid microcarcinoma}

\begin{tabular}{|c|c|}
\hline Journal: & Histopathology \\
\hline Manuscript ID: & HISTOP-04-10-0248 \\
\hline Manuscript Type: & Original Article \\
\hline $\begin{array}{r}\text { Date Submitted by the } \\
\text { Author: }\end{array}$ & 28-Apr-2010 \\
\hline Complete List of Authors: & $\begin{array}{l}\text { Koperek, Oskar; Medical University of Vienna, Clinical Pathology } \\
\text { Asari, Reza; Medical University of Vienna, Department of Surgery } \\
\text { Niederle, Bruno; Medical University of Vienna, Department of } \\
\text { Surgery } \\
\text { Kaserer, Klaus; Medical University of Vienna, Clinical Pathology }\end{array}$ \\
\hline Keywords: & $\begin{array}{l}\text { papillary thyroid microcarcinoma, desmoplasia, lymph node } \\
\text { metastasis }\end{array}$ \\
\hline
\end{tabular}

\section{S) ScholaroNE \\ Manuscript Central}




\section{Desmoplastic stroma reaction in papillary thyroid microcarcinoma}

Oskar Koperek $^{1}$ (OK); Reza Asari ${ }^{2}$ (CS); Bruno Niederle ${ }^{2}$ (BN); and Klaus Kaserer ${ }^{1}$ (KK)

${ }^{1}$ Department of Clinical Pathology, Medical University of Vienna; ${ }^{2}$ Section of Endocrine

Surgery, Division of General Surgery, Department of Surgery, Medical University of Vienna,

Austria

\section{Corresponding Address:}

Klaus Kaserer, MD

Department of Clinical Pathology

Medical University of Vienna

Währinger Gürtel 18-20

A-1090 Vienna, Austria

FAX: 043-1-40400-3707

Telephone number: 043-1-40400-3650

Email: klaus.kaserer@meduniwien.ac.at

Running title: Desmoplasia in papillary microcarcinoma

Key words: papillary thyroid microcarcinoma; desmoplasia; lymph node metastasis 
Koperek et al -2-.

\section{Abstract}

Aims: To evaluate the value of desmoplastic stroma reaction (desmoplasia) as an indicator of metastasis in papillary thyroid microcarcinoma (PTC).

Methods and result: Hundred and nine cases of papillary thyroid microcarcinoma from the pathological archive of the Medical University of Vienna, Austria, were analyzed for the presence of desmoplasia in relation to other morphologic and clinicopathologic parameters 81/109 papillary microcarcinomas showed a desmoplastic stroma reaction. The desmoplasia was significantly associated with lymph node metastases $(p=0.001)$ and tumour diameter $(p<$ 0.001). In addition "invasive parameters", like peritumoral and vascular invasion were associated with the presence of a desmoplastic stroma reaction ( $p<0.001$ and $p=0.006$, respectively) and all pT3b tumours according to the UICC classification of 2002 (=with perithyroidal infiltration) showed a desmoplasia. Of all morphologic parameters the best indicator of lymph node metastasis was tumour calcification $(p<0.001)$.

Conclusion: Our data indicate that desmoplastic stroma reaction seems to be an indicator of an invasive behaviour of papillary thyroid microcarcinomas significantly associated with lymph node metastases. Papillary microtumours without signs of invasion, e.g. desmoplasia should not be regarded as invasive carcinoma as they are more likely thyroidal intraepithelial neoplasias. 


\section{Introduction}

Papillary thyroid microcarcinoma is defined as a papillary thyroid carcinoma (PTC) with a tumour diameter of $10 \mathrm{~mm}$ or less. ${ }^{1,2}$ In the past microcarcinomas were often found incidentally after pathologic examination of thyroidectomy specimens operated for other reasons, e.g. multinodular goiter, follicular adenoma or Graves disease, but with the increasing use of ultrasonography and fine needle aspiration biopsy in nodules $<10 \mathrm{~mm}$, clinically unapparent microcarcinoma were also detected more often preoperatively. Not surprisingly the incidence of surgically removed thyroid microcarcinomas increased in the last years. ${ }^{3,4}$ The frequency of these small tumours in autopsy studies and in surgical thyroidectomies varies between 5 and $36 \% .^{5-9}$

In many studies papillary thyroid microcarcinomas exhibit an excellent clinical course with a low disease related mortality rate, however some of the papillary microcarcinomas were associated with local recurrence or distant metastases, and lymph node metastasis are detected in a significant portion (up to $50 \%$ ). ${ }^{10-15}$

Regarding morphologic parameters in papillary microcarcinoma some studies found multifocality, tumour size or extension through the thyroid capsule significantly associated with lymph node metastasis or recurrent disease but others did not. ${ }^{11,14,16,17}$ Investigating the metastatic behaviour in other thyroid tumours, namely medullary carcinoma we found that tumours without a desmoplastic stroma reaction (desmoplasia) did not show lymph node metastasis. ${ }^{18,19}$ Characterizing the desmoplastic stroma of medullary carcinoma we found a similar stroma reaction in a few control cases of other thyroid carcinomas including PTC. ${ }^{20}$ A subsequent in silico expression analysis of stromal components, namely fibroblast activation protein and tenascin $\mathrm{C}$ revealed an 4.2 fold and 2.8 fold upregulation in lymph node positive compared to lymph node negative PTCs, respectively. ${ }^{20}$ 
With the present work we investigate the desmoplastic stroma reaction in papillary microcarcinoma with the aim to identify a fraction of papillary microtumours without metastatic potential on a morphologic basis. 


\section{Material and Methods}

We analyzed 109 cases of histological proven papillary microcarcinoma (tumour diameter: $10 \mathrm{~mm}$ or less) retrieved from the archives of the Department of Pathology of the Medical University of Vienna diagnosed between 2000 and 2006. Only cases with clinicopathologic data including sex, age, tumour size and lymph node status were selected.

Total thyroidectomy was performed in all patients. The thyroid samples were routinely processed at the Department of Pathology, Medical University of Vienna. The entire organ was sectioned horizontally in slices of approximately $3-5 \mathrm{~mm}$ and formalin fixed.

Representative slices from the upper, middle and bottom region of each lobe and additionally from every suspect lesion were embedded in paraffin.

In all cases resected lymph nodes at least from the central cervical compartment were available for histological analysis. In case of histologically proven lymph node metastasis of a papillary thyroid carcinoma and macroscopically inconspicuous thyroid gland, the whole organ was embedded in 2-3 mm thick slices and processed for histological evaluation. $3 \mu \mathrm{m}$ sections of each block were cut and stained with haematoxylin and eosin.

All papillary thyroid carcinomas were classified according to the World Health Organization criteria outlined in $2004^{2}$ and staged according to the International Union Against Cancer (UICC) 2002 guidelines and its supplement 2003. ${ }^{21,22}$

Histology

Desmoplastic stroma reaction (desmoplasia) was defined, as the presence of a newly formed fibrotic (collagenous) stroma surrounding the invasive epithelial tumour cells not found in the non-neoplastic thyroid parenchyma. 
The presence of a desmoplastic stroma reaction within the tumour was determined retrospectively on HE-stained sections by author OK. For interobserver analyses the presence of desmoplastic stroma reaction was classified by author KK in a blinded manner. Both authors are pathologists with special expertise in thyroid pathology. Additionally we assessed growth patterns, the peritumoral infiltration pattern, vascular invasion, presence of intratumoural lymphocytes and calcification.

\section{Statistical Evaluation}

For statistical analysis, the SPSS program (SPSS, Chicago, IL) was used. For statistical analysis of the interobserver reliability the Cohen-Kappa-coefficient was calculated. The value 1 means total agreement whereas the value 0 means that the agreement does not exceed the random measure. For comparative analysis chi-square calculations and the Mann Whitney test were applied whenever appropriate. $P$ values $\leq 0.05$ were considered significant. 


\section{Results}

\section{Patient Data and morphologic parameters:}

Patient data, morphologic characteristics of the tumours and correlations with metastatic behaviour are listed in table 1.

Of the 109 cases of papillary microcarcinomas lymph node metastases were found in $25.7 \%$ $(n=28), 92.6 \%(n=101)$ of the tumours were classified as pT1a whereas $7.4 \%(n=8)$ of the microtumours infiltrated the perithyroidal tissue and were hence classified as pT3b according to the UICC guidelines. Multifocal PTC was present in $37.6 \%(n=41)$ of the patients. A desmoplastic stroma reaction (see figure 1a) was found either in the entire tumour or focally in a majority of the cases $(74.3 \% ; n=81)$ with the remaining cases $(25.7 \% ; n=28)$ showing no desmoplasia (see figure 1b). Interobserver variability (author OK vs. author KK) in assessing desmoplasia was low. A concordant result was found in $93.6 \%(n=102$; Cohen kappa coefficient $=0.841$ )

Associated thyroid pathology revealed nodular goiter in $77.1 \%(n=84)$, lymphocytic thyroiditis in $37.6 \%(n=41)$ and other malignant thyroid neoplasms in $20.2 \%(n=22$; seventeen medullary thyroid carcinoma, four follicular thyroid carcinoma and one MALT lymphoma). Follicular thyroid adenoma was detected in $7.3 \%(n=8)$.

\section{Correlation of desmoplastic stroma reaction with clinicopathologic and morphologic} parameters

The desmoplastic stroma reaction was significantly associated with vascular invasion, tumour calcification, peritumoral infiltration, tumour diameter and lymph node metastasis $\left(\mathrm{p}_{\text {vascular }}\right.$ invasion $=0.006, p_{\text {calcification }}=0.007, p_{\text {peritumoral infiltration }}<0.001, p_{\text {tumour diameter }}<0.001 ; p_{\text {lymph node }}=$ 
0.001). All pT3 tumours (=with perithyroidal infiltration) showed a desmoplastic stroma reaction.

All but one of the cases with lymph node metastasis showed a desmoplastic stroma reaction in the primary tumour. This one patient was operated primarily because of hyperplastic parathyroid glands. In the postoperative work up a macroscopically inconspicuous lymph node from the central neck showed a group of thyroid follicles within its parenchyma interpreted as an incidental micrometastasis of a PTC. The subsequently removed thyroid gland displayed extensive postoperative bleeding, necrosis, and a small (0.4 millimetre in diameter) papillary microcarcinoma without desmoplastic stroma reaction (see figure 2).

\section{Correlation of lymph node metastasis with clinicopathologic and morphologic} parameters (see table 1)

In addition to desmoplastic stroma reaction the presence of lymph node metastasis was significantly associated with tumour calcification, tumour diameter, vascular invasion, peritumoral invasion, perithyroidal invasion (pT1 vs. pT3b tumours), multifocality, absence of lymphocytic thyroiditis, and younger age $\left(p_{\text {calcification }}<0.001 ; p_{\text {tumour diameter }}=0.036, p_{\text {vascular }}\right.$ invasion $=0.003 ; p_{\text {peritumoral invasion }}=0.003, p_{\text {perithyroidal invasion }}=0.029 ; p_{\text {multifocality }}=0.023 ; p_{\text {lymphocytic }}$ thyroiditis $=0.013 ; p_{\text {age }}=0.03$ ). 


\section{Discussion}

The desmoplastic stroma reaction in cancer is composed of activated fibroblasts expressing a-smooth muscle actin, fibroblast activation factor (FAP) and extracellular matrix proteins, e.g. tenascin C, analogous to the wound healing stroma. ${ }^{20}$ It has been suggested to represent an important player in the development of the invasion process. ${ }^{23,}{ }^{24}$ Using in silico expression analyses we observed upregulation of FAP and tenascin C expression in metastasizing vs. not metastasizing PTC. In the present study we investigated if desmoplastic stroma reaction is seen early in tumorigenesis of PTC and if the absence of desmoplastic stroma reaction indicates a "preinvasive" form of a PTC. In our cases of papillary thyroid microcarcinoma the presence of desmoplasia was significantly associated with morphologic parameters of invasion, namely peritumoral invasion and vascular invasion as well as lymph node metastasis. The absence of a desmoplastic stroma on the other hand was strongly indicative of a non invasive, non metastasizing tumour, and can probably be used as a diagnostic/prognostic parameter in assessing the metastatic potential of papillary microcarcinoma.

A link of stroma reaction and invasive growth in PTC was also indicated by other authors. Harach et al. reported that significant fibrosis was found in $79 \%$ of occult PTCs with invasive growth pattern as opposed to their circumscribed tumours which showed only slight fibrosis. ${ }^{7}$ A study by Mai et al. compared so called "infiltrating" PTC defined by a sclerotic stroma with non infiltrating tumours and found that only one encapsulated non infiltrating tumour showed lymph node metastases. ${ }^{25}$ Unfortunately they do not describe the size of the tumour or if the tumour was completely embedded for histological examination to find focal infiltrative growth pattern. 
In our series only one case of papillary thyroid microcarcinoma without desmoplasia showed a lymph node metastasis. Revaluation of the lymph node metastasis displayed a follicular arrangement of thyroid cells (see figure $2 \mathrm{~b}$ ) which might also be interpreted as ectopic thyroid tissue. Although the existence of ectopic thyroid tissue in a lymph node is discussed controversially ${ }^{26}$, we think that we cannot exclude that possibility in this case. A more likely explanation however could be that we failed to detect a second PTC lesion with desmoplasia in the area of postoperative necrosis, bleeding and inflammation (see figure $2 c$ ).

Similar to other studies the presence of lymph node metastases as well as desmoplasia correlated with the tumour diameter. ${ }^{16,27}$ This indicates a possible progression of a papillary thyroid neoplasia without desmoplasia i. e. without invasive behaviour into an invasive tumour with desmoplasia and the possibility of lymph node metastasis. Yamamoto et al. found a similar result classifying occult PTC in three types, namely encapsulated, non encapsulated sclerosing and nonsclerosing types. The mean size of non sclerosing PTC was significantly smaller than the tumour size of the sclerosing type. In this study only 2/42 tumours showed lymph node metastasis, both of the sclerosing type with calcification. ${ }^{8}$

In our study tumour calcification showed the highest level of significance of all morphologic parameter associated with lymph node metastasis $(p<0,001)$. Similar observations were made in a recent study investigating calcification in papillary thyroid carcinoma ${ }^{28}$ They show that psammoma bodies and stromal calcification in the primary tumour are strongly associated to the presence of gross lymph node metastasis. However since calcification or psamomma bodies were not seen in the absence of desmoplasia we consider calcification not as an independent parameter but rather a consequence of the stromal desmoplasia. The presence of lymphocytic thyroiditis was inversely correlated with lymph node metastasis. These findings corroborate previously observations in Hashimoto`s thyroiditis that an autoimmune reaction might be protective of the development of lymph node metastases. ${ }^{16}$ 
In conclusion our data indicate that desmoplastic stroma reaction seems to be a reliable indicator of an invasive behaviour of papillary thyroid microcarcinomas. In particular in combination with calcification desmoplasia is significantly associated with lymph node metastases. Our study suggests that papillary microtumours without signs of invasion, e.g. desmoplasia, should probably not be regarded as invasive carcinoma but rather as thyroidal intraepithelial neoplasms. 


\section{References}

1. Hedinger C, Young R, Sobin L. WHO. Histologic Typing of Thyroid Tumors. New York: Springer-Verlag, 1988.

2. DeLellis R, Lloyd R, Heitz PU, Eng C. Pathology and Genetics of Tumors of the Endocrine Organs. Kleihues P, Sobin L, editors. Lyon: IARC, 2004.

3. Davies L, Welch HG. Increasing incidence of thyroid cancer in the United States, 19732002. Jama. 2006; 295(18); 2164-2167.

4. Colonna M, Guizard AV, Schvartz C, Velten M, Raverdy N, Molinie F, et al. A time trend analysis of papillary and follicular cancers as a function of tumour size: a study of data from six cancer registries in France (1983-2000). Eur J Cancer. 2007; 43(5); 891-900.

5. Lang W, Borrusch H, Bauer L. Occult carcinomas of the thyroid. Evaluation of 1,020 sequential autopsies. Am J Clin Pathol. 1988; 90(1); 72-76.

6. de Matos PS, Ferreira AP, Ward LS. Prevalence of papillary microcarcinoma of the thyroid in Brazilian autopsy and surgical series. Endocr Pathol. 2006; 17(2); 165-173.

7. Harach HR, Franssila KO, Wasenius VM. Occult papillary carcinoma of the thyroid. A "normal" finding in Finland. A systematic autopsy study. Cancer. 1985; 56(3); 531-538.

8. Yamamoto Y, Maeda T, Izumi K, Otsuka H. Occult papillary carcinoma of the thyroid. A study of 408 autopsy cases. Cancer. 1990; 65(5); 1173-1179.

9. Baloch ZW, LiVolsi VA. Microcarcinoma of the thyroid. Adv Anat Pathol. 2006; 13(2); 6975.

10. Roti E, degli Uberti EC, Bondanelli M, Braverman LE. Thyroid papillary microcarcinoma: a descriptive and meta-analysis study. Eur J Endocrinol. 2008; 159(6); 659-673. 
11. Pazaitou-Panayiotou K, Capezzone M, Pacini F. Clinical features and therapeutic implication of papillary thyroid microcarcinoma. Thyroid. 2007; 17(11); 1085-1092.

12. Hay ID, Grant CS, van Heerden JA, Goellner JR, Ebersold JR, Bergstralh EJ. Papillary thyroid microcarcinoma: a study of 535 cases observed in a 50-year period. Surgery. 1992; 112(6); 1139-1146; discussion 1146-1137.

13. Baudin E, Travagli JP, Ropers J, Mancusi F, Bruno-Bossio G, Caillou B, et al. Microcarcinoma of the thyroid gland: the Gustave-Roussy Institute experience. Cancer. 1998; 83(3); 553-559.

14. Chow SM, Law SC, Chan JK, Au SK, Yau S, Lau WH. Papillary microcarcinoma of the thyroid-Prognostic significance of lymph node metastasis and multifocality. Cancer. 2003; 98(1); 31-40.

15. Sugino K, Ito K, Jr., Ozaki O, Mimura T, Iwasaki H, Ito K. Papillary microcarcinoma of the thyroid. J Endocrinol Invest. 1998; 21(7); 445-448.

16. Roti E, Rossi R, Trasforini G, Bertelli F, Ambrosio MR, Busutti L, et al. Clinical and histological characteristics of papillary thyroid microcarcinoma: results of a retrospective study in 243 patients. J Clin Endocrinol Metab. 2006; 91(6); 2171-2178.

17. Kim TY, Hong SJ, Kim JM, Gu Kim W, Gong G, Ryu JS, et al. Prognostic parameters for recurrence of papillary thyroid microcarcinoma. BMC Cancer. 2008; 8 (296.

18. Kaserer K, Scheuba C, Neuhold N, Weinhausel A, Haas OA, Vierhapper H, et al. Sporadic versus familial medullary thyroid microcarcinoma: a histopathologic study of 50 consecutive patients. Am J Surg Pathol. 2001; 25(10); 1245-1251.

19. Koperek O, Scheuba C, Cherenko M, Neuhold N, De Micco C, Schmid KW, et al. Desmoplasia in medullary thyroid carcinoma: a reliable indicator of metastatic potential. Histopathology. 2008; 52(5); 623-630. 
20. Koperek O, Scheuba C, Puri C, Birner P, Haslinger C, Rettig W, et al. Molecular characterization of the desmoplastic tumor stroma in medullary thyroid carcinoma. Int $J$ Oncol. 2007; 31(1); 59-67.

21. Sobin L, Wittekind C. TNM classification of malignant tumours. 6th ed. New York: WileyLiss, 2002.

22. Wittekind C, Greene F, Henson D, Hutter R, Sobin L. TNM supplement. A commentary on uniform use. 3rd ed. New York: Wiley-Liss, 2003.

23. De Wever O, Mareel M. Role of tissue stroma in cancer cell invasion. J Pathol. 2003; 200(4); 429-447.

24. Dvorak HF. Tumors: wounds that do not heal. Similarities between tumor stroma generation and wound healing. N Engl J Med. 1986; 315(26); 1650-1659.

25. Mai KT, Perkins DG, Yazdi HM, Commons AS, Thomas J, Meban S. Infiltrating papillary thyroid carcinoma: review of 134 cases of papillary carcinoma. Arch Pathol Lab Med. 1998; 122(2); 166-171.

26. Rosai J, Carangiu M, DeLellis R. Atlas of Tumor Pathology: Tumors of the Thyroid Gland. Washington DC: Armed Forces Institute of Pathology, 1992.

27. Wada N, Duh QY, Sugino K, Iwasaki H, Kameyama K, Mimura T, et al. Lymph node metastasis from 259 papillary thyroid microcarcinomas: frequency, pattern of occurrence and recurrence, and optimal strategy for neck dissection. Ann Surg. 2003; 237(3); 399407.

28. Bai Y, Zhou G, Nakamura M, Ozaki T, Mori I, Taniguchi E, et al. Survival impact of psammoma body, stromal calcification, and bone formation in papillary thyroid carcinoma. Mod Pathol. 2009; 22(7); 887-894. 
Table 1. Clinicopathologic/Morphologic Parameters and Lymph Node Metastasis

\begin{tabular}{|c|c|c|c|c|c|}
\hline & & $\begin{array}{c}\mathrm{mPTC} \\
\text { total }\end{array}$ & $\begin{array}{l}\text { mPTC with } \\
\text { LN-Meta }\end{array}$ & $\begin{array}{l}\text { mPTC without } \\
\text { LN-Meta }\end{array}$ & $\begin{array}{l}\text { Significant } \\
\text { p-values }\end{array}$ \\
\hline \multicolumn{2}{|l|}{ Age (in years) } & $\begin{array}{l}52,7 \pm 13 \\
(19-78)\end{array}$ & $\begin{array}{c}47,5 \pm 14,4 \\
(19-75) \\
\end{array}$ & $\begin{array}{c}54,3 \pm 12,1 \\
(26-78) \\
\end{array}$ & $p=0,03$ \\
\hline \multirow[t]{2}{*}{ Sex } & Male & $46 / 109$ & $15 / 28$ & $31 / 81$ & \\
\hline & Female & $63 / 109$ & $13 / 28$ & $50 / 81$ & \\
\hline \multicolumn{2}{|c|}{ Tumour diameter (mm) } & $\begin{array}{l}3,8 \pm 2,7 \\
(0,4-10)\end{array}$ & $\begin{array}{c}4,7 \pm 3 \\
(0,4-10)\end{array}$ & $\begin{array}{l}3,5 \pm 2,6 \\
(0,4-10)\end{array}$ & $p=0,036$ \\
\hline & 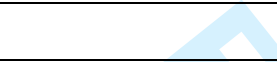 & $41 / 109$ & $16 / 28$ & $25 / 81$ & $p=0,023$ \\
\hline \multirow{2}{*}{ Desmoplasia } & No & $28 / 109$ & $1 / 28$ & $27 / 81$ & \multirow{2}{*}{$p=0,001$} \\
\hline & yes & $81 / 109$ & $27 / 28$ & $54 / 81$ & \\
\hline \multirow[t]{2}{*}{ Growth pattern } & $\begin{array}{l}\text { Classic } \\
\text { (papillary and } \\
\text { mixed) }\end{array}$ & $65 / 109$ & $19 / 28$ & $46 / 81$ & \\
\hline & $\begin{array}{l}\text { Exclusively } \\
\text { follicular }\end{array}$ & $44 / 109$ & $9 / 28$ & $35 / 81$ & \\
\hline \multicolumn{2}{|c|}{ Extrathyroidal invasion } & $8 / 109$ & $5 / 28$ & $3 / 81$ & $p=0,029$ \\
\hline \multicolumn{2}{|c|}{ Peritumoural invasion } & $77 / 109$ & $26 / 28$ & $51 / 81$ & $p=0,003$ \\
\hline \multicolumn{2}{|c|}{ Vascular invasion } & $18 / 109$ & $10 / 28$ & $8 / 81$ & $p=0,003$ \\
\hline \multicolumn{2}{|c|}{ Encapsulation } & $18 / 109$ & $3 / 28$ & $15 / 81$ & \\
\hline \multicolumn{2}{|c|}{ Tumour calcification } & $23 / 109$ & $14 / 28$ & $9 / 81$ & $p<0,001$ \\
\hline \multicolumn{2}{|c|}{$\begin{array}{l}\text { Lymphocytes within the tumour } \\
\text { stroma }\end{array}$} & $25 / 109$ & $5 / 28$ & $20 / 81$ & \\
\hline \multirow{3}{*}{$\begin{array}{l}\text { Inflammation in } \\
\text { the prexisting } \\
\text { thyroid tissue }\end{array}$} & No & $68 / 109$ & $23 / 28$ & $45 / 81$ & \multirow{3}{*}{$p^{* *}=0,013$} \\
\hline & Little & $25 / 109$ & $2 / 28$ & $23 / 81$ & \\
\hline & $\begin{array}{l}\text { Moderate/ } \\
\text { Prominent }\end{array}$ & $16 / 109$ & $3 / 28$ & $13 / 81$ & \\
\hline
\end{tabular}

mPTC: papillary thyroid microcarcinoma; LN-Meta: lymph node metastasis, $\mathrm{p}^{* *}$ : thyroiditis (little to prominent) vs. no thyroiditis 
Titles and legends to figures

Figure 1. Papillary thyroid microcarcinoma and desmoplasia

A: Papillary thyroid microcarcinoma with demoplastic stroma reaction; B: Papillary thyroid microcarcinoma without desmoplastic stroma reaction.

Figure 2. Papillary thyroid microcarcinoma without desmoplasia but with lymph node metastasis

A: Papillary thyroid microcarcinoma without demoplastic stroma reaction; B: Normal looking thyroid follicles in a lymph node interpreted as a metastasis of a papillary thyroid carcinoma (localisation: right central neck); C: Extensive postoperative thyroid necrosis and bleeding in the same case. 

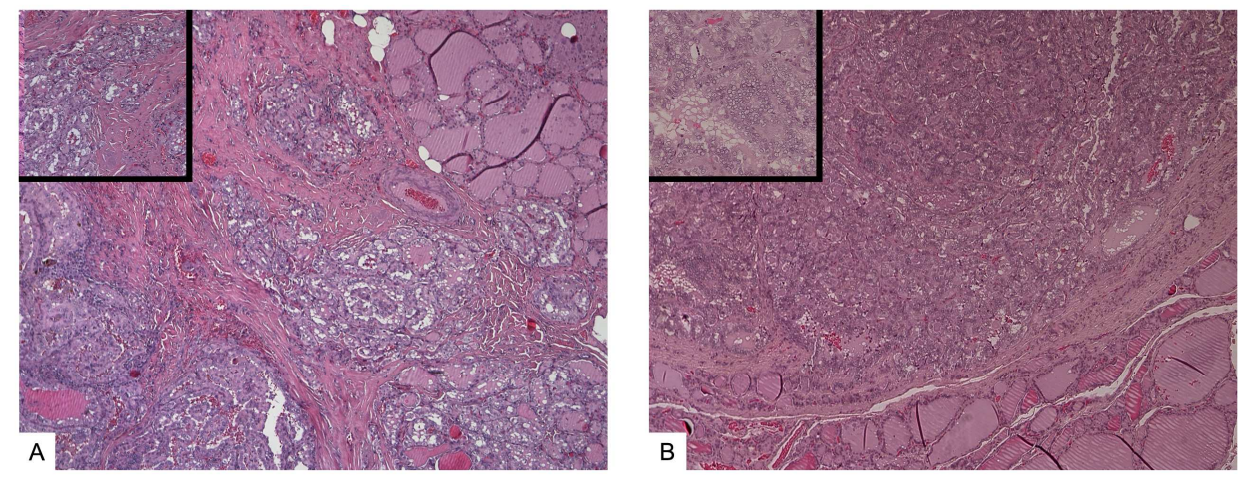

$154 \times 65 \mathrm{~mm}(450 \times 450$ DPI $)$ 

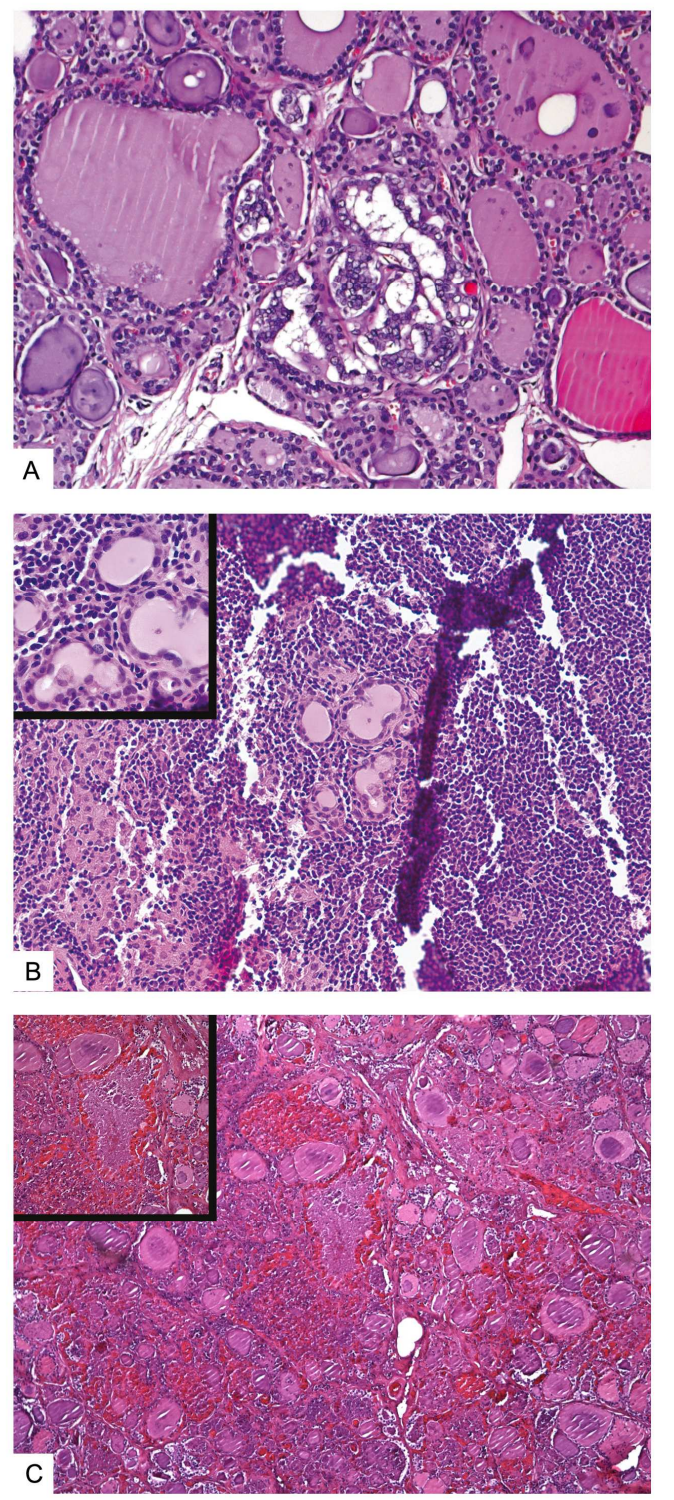

$89 \times 196 \mathrm{~mm}(400 \times 400 \mathrm{DPI})$ 